\title{
Peripheral venous thrombophlebitis risk and the role of hand washing
}

\author{
Neopane $A^{1^{*}}$ \\ ${ }^{1}$ Department of Medicine, Kathmandu Medical college Teaching Hospital, Kathmandu, Nepal
}

\author{
* Corresponding Author: \\ Dr Arpana Neopane \\ Associate Professor \\ Department of Medicine \\ Kathmandu Medical College \\ Sinamangal, Kathmandu \\ Email: arpana.neopane@gmail.com
}

\section{Citation}

Neopane A. Peripheral venous thrombophlebitis risk and the role of hand washing. Nepal Journal of Medical Sciences 2013;2(1):26-9.

\begin{abstract}
Background: Thrombophlebitis is an important complication of peripheral vein cannulation. Various factors are known to increase the risk of thrombophlebitis and have been studied by different authors. Regarding factors leading to risk reduction of thrombophlebitis aseptic measures taken during insertion has been an important factor. However handwashing and its role in reducing the incidence of thrombophlebitis have not been studied. The objective of this study was to find the risk reducing role of hand washing in incidence of thrombophlebitis
\end{abstract}

Methods: A prospective observational hospital based study was designed and conducted among patients admitted for intravenous medication or infusion and needed cannulation. They were followed and evaluated for various risk factors and onset of thrombophlebitis. Results expressed as relative risk and odds ratio.

Results: Hand washing is the single most important risk reducing factor for development of peripheral vein thrombophlebitis in patients in whom peripheral vein cannulation is done. The odds ratio of developing thrombophlebitis in hand washing group was only 0.25 (95\% CI .07-.82) and RR was 0.78 (95\% CI.64-.94) with $\mathrm{p}=.017$.

Conclusion: Six step hand washing was the single most useful factor for reducing the risk of thrombophlebitis.

Keywords: Peripheral vein cannulation; thrombophlebitis; asepsis; hand washing,

\section{Background:}

Intravenous cannulation is used for the administration of intravenous medication, fluids, blood and forms integral part of medical inpatient ward. ${ }^{1}$ But very often it is complicated by thrombophlebitis which is self limiting inflammation and thrombosis of superficial veins characterized by pain redness and swelling and venous obstruction. ${ }^{2}$ It is most common cause of fever and prolonged hospital stay after the recovery from the primary disease. It has both patientrelated implications like sepsis and economic consequences like extra nursing time. Thus adds to the morbidity and economic burden to the patients. Studies show that the incidence of thrombophlebitis in hospitalized patients is quite high and the rate varies from $5.3 \%$ to $77.5 \%{ }^{2,3}$ Although various studies have highlighted the importance of 
following strict asepsis before insertion to decrease the risk of thrombophlebitis ${ }^{5,6}$ none have addressed the role of six step hand washing. Hence a prospective study was designed to evaluate the effect of hand washing in decreasing the risk of peripheral vein thrombophlebitis. As various factors are known to increase the incidence of thrombophlebitis ${ }^{7-9}$ this study was also done to evaluate the role of factors like site and place of catheter insertion, cannula material, drugs used, duration of catheterization and associated co morbidity like diabetes.

Methods: Prospective observational study was carried out. The study was conducted in the in- patient ward of department of medicine of a Medical college located in Kathmandu, Nepal. A total of 100 patients were enrolled in the study done in the month of June 2011.

Patients to be admitted to the medical wards needing intravenous cannula were cannulated randomly at the emergency (ER) or the ward as the clinical situation demanded. All the cannulating nurses were detailed about the nature of the study almost one week before case collection and were asked to follow strict aseptic precautions in the following sequence: shaving the area, then six step hand washing, cleaning with spirit, then betadine. The cannula used was not standardized and depending on the availability, two types were used: B Braun and BD venflon as brought by the patient party. The adhesive dressing was also not specified and used as per availability. Then duty doctors involved in the study entered the patient in the performa prepared and made detailed record of the following variables: Age, Sex, Diagnosis, cannula type,size of cannula, ward or ER insertion and aseptic precautions before insertion: shaving of the area, hand wash, spirit cleaning, betadine cleaning, adhesive used, site of cannula insertion without making the inserter biased on a particular site. Then two medical officers responsible for the follow up inspected and palpated the insertion site every day to pick the signs of thrombophlebitis. Appearance of phlebitis was defined as: appearance of redness, pain and tenderness with or without swelling at the site of cannula insertion and along the vein, with or without fever and blockage of the intravenous flow. Every day evaluation was done for redness, tenderness, swelling, fever, and obstruction at the insertion site and noted as appearance on d1 (24hrs), d2 (48hrs) etc. Cannulation was maintained on heparin lock or with fluid infusion. Type of infusate and medication given were also noted. Data was analyzed using SPSS version 17 . Risk of developing thrombophlebitis was expressed as Odds Ratio (OR) and Relative (RR). Different variables were compared with chi squared test with $\mathrm{p}$ value $<0.05$ taken as significant.

Results: Mean age of the study cohort was 47.46 \pm 21.28 . Females outnumbered the males and ratio was 1.3:1. A significant number of patients (79\%) developed thrombophlebitis highlighting the severity of the problem in our setting. Females developed significantly more $(p=0.06)$ thrombophlebitis than the male. Shaving the site of insertion was only done in 2 cases. Spirit cleaning was done in all. Betadine cleaning was done in $23 \%$ and hand washing was only done in $58 \%$, inspite of strict instruction to do it before each cannulation. The most significant measure of asepsis to decrease the risk of thrombophlebitis was hand washing $(\mathrm{p}=0.017)$ as shown in Table 1 .

Table1: Relation of Patient characteristics, material and technique to thrombophlebitis

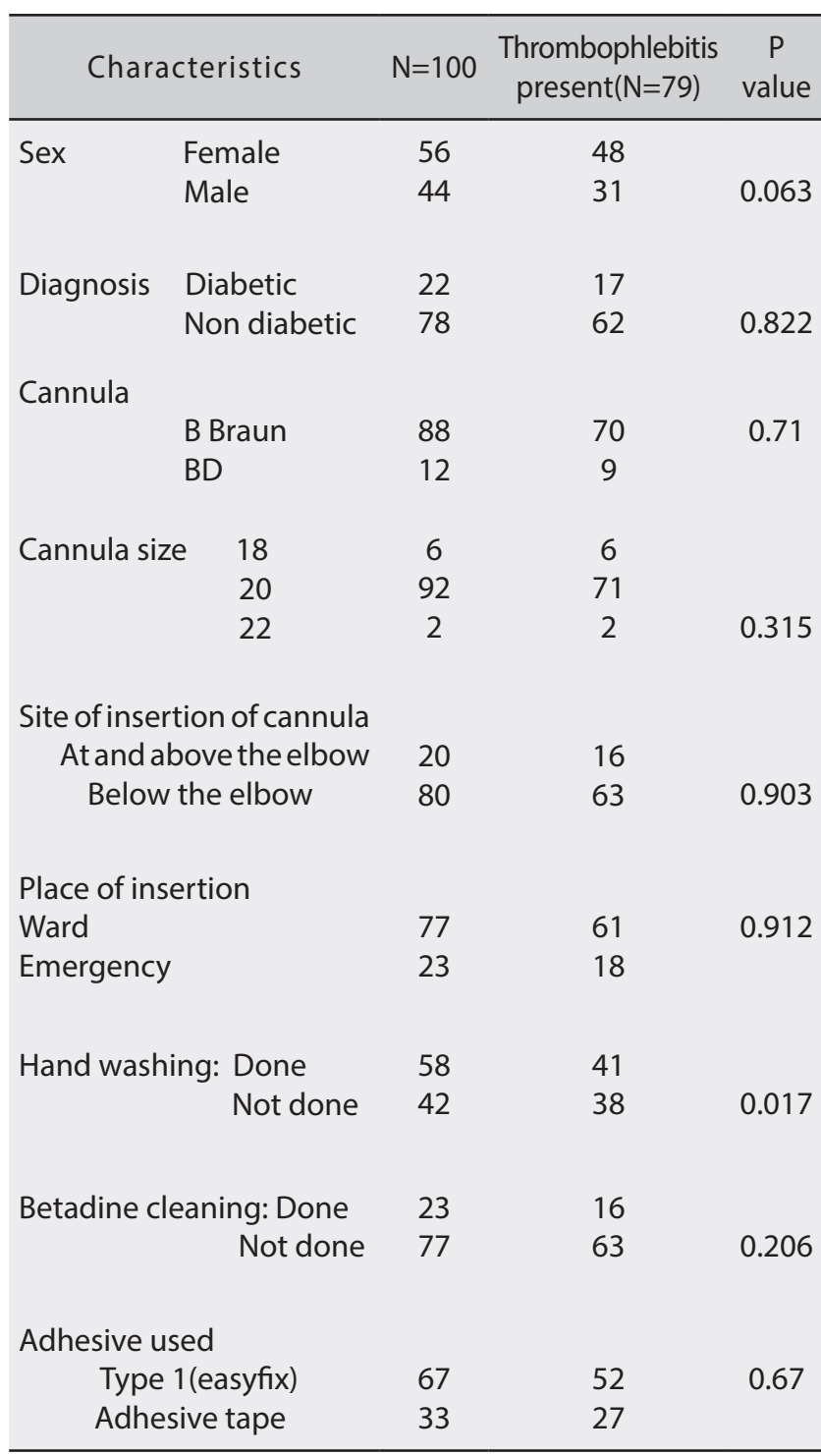

The odds ratio of developing thrombophlebitis in hand washing group was only $0.25(95 \% \mathrm{CI}=0.07-0.82)$ and $\mathrm{RR}$ was $0.78(95 \% \mathrm{CI}=0.64-0.94)$. The RR of thrombophlebitis 
being absent in hand washing group was $3.1(95 \% \mathrm{CI}=1.1$ 8.4). Other risk factors for thrombophlebitis are shown in Table 2.

Table 2: Risk of developing thrombophlebitis

\begin{tabular}{|c|c|c|c|}
\hline Variables & $\begin{array}{l}\text { Odds Ratio } \\
(95 \% \mathrm{Cl})\end{array}$ & $\begin{array}{c}\text { Relative Risk } \\
(95 \% \mathrm{Cl}) \\
\text { Thrombophlebitis } \\
\text { present }\end{array}$ & $\begin{array}{c}\text { Relative Risk } \\
(95 \% \mathrm{Cl}) \\
\text { Thrombophlebitis } \\
\text { absent }\end{array}$ \\
\hline Sex & $2.5(.94-6.8)$ & $1.2(.98-1.5)$ & $.48(.2-1.1)$ \\
\hline $\begin{array}{l}\text { Cannulation } \\
\text { site } \\
\text { Aboveelbow/ } \\
\text { below elbow }\end{array}$ & $.72(.28-1.8)$ & $.93(.76-1.1)$ & $1.3(.60-2.8)$ \\
\hline $\begin{array}{l}\text { Place of } \\
\text { cannulation } \\
\text { (Ward/ER) }\end{array}$ & $1.1(.34-3.2)$ & $1.01(.8-1.3)$ & $.96(.4-2.6)$ \\
\hline $\begin{array}{l}\text { Type of } \\
\text { cannula } \\
\text { BB/BD }\end{array}$ & $1.3(.32-5.3)$ & $1.1(.75-1.5)$ & $.82(.28-2.4)$ \\
\hline $\begin{array}{l}\text { handwashing } \\
\text { Yes/No }\end{array}$ & $.25(.07-.82)$ & $.78(.64-.94)$ & $3.1(1.1-8.4)$ \\
\hline $\begin{array}{l}\text { Betadine } \\
\text { cleaning Yes/ } \\
\text { NO }\end{array}$ & $.51(.18-1.5)$ & $.85(.64-1.1)$ & $1.7(.77-3.6)$ \\
\hline $\begin{array}{l}\text { Adhesiveused } \\
\text { Type 1/Type } 2\end{array}$ & $.77(.27-2.3)$ & $.95(.77-1.2)$ & $1 ` .2(.5-2.9)$ \\
\hline $\begin{array}{l}\text { Allmethodsof } \\
\text { asepsis done } \\
\text { Yes/No }\end{array}$ & $.58(.14-2.5)$ & $.87(.58-1.3)$ & $1.5(.53-4.2)$ \\
\hline $\begin{array}{l}\text { Diabetes } \\
\text { Yes/No }\end{array}$ & $.88(.28-2.7)$ & $.97(.76-1.3)$ & $1.1(.46-2.7)$ \\
\hline
\end{tabular}

Regarding signs of thrombophlebitis, fever was present in $38 \%$, redness and tenderness in $74.7 \%$, swelling with tenderness and redness in $57 \%$, and obstruction leading to removal of the cannula $12.7 \%$. Surprisingly the thrombophlebitis was detected even after 24 hours though the maximum cases were detected after 48 hours. The incidence decreased after the $72 \mathrm{hrs}$. The site of the cannula insertion showed that insertion at and above the elbow (cubital fossa) was associated with less risk of thrombophlebitis than below elbow $\mathrm{RR}=1.3(95 \% \mathrm{CI}=0.60-2.8)$. The odds of developing thrombophlebitis with cannula at (cubital fossa) and above elbow was only $0.72(95 \% \mathrm{CI}=0.28-1.8)$ and the RR was $0.93(95 \% \mathrm{CI}=0.76-1.1)$. Regarding the infusate used, dextrose based fluid (not shown in table) was associated with increased incidence of thrombophlebitis $(p=0.067)$. Heparin lock and drugs used did not seem to affect the incidence of thrombophlebitis. Diabetes was not associated with significant increase in incidence of thrombophlebitis.

Discussions: Thrombophlebitis is a very common condition in our setting. Measures to decrease its incidence will save a lot of time and money for the patient and the health care institution both. A simple process of asepsis followed before cannulation leads to decrease in the incidence of thrombophlebitis. ${ }^{10-12}$ Our study is unique as it has studied and has shown the positive role of six step hands washing before cannula insertion in decreasing the incidence significantly. However the lack of motivation on the part of the nurses for handwashing, was worrying. Similar results regarding non interest for hand washing was shown in other studies. ${ }^{13,14}$ This shows that inspite of handwashing being the single most important method to decrease any type of health care associated infection; we have not been able to highlight the importance of hand washing to our staffs.

Different studies have shown various other risk factors for thrombophlebitis ${ }^{1}$ Duration of cannulation is a very important risk factor ${ }^{15,16}$ and the incidence rises after 48 hrs. Our study however has shown that although the risk sharply rises after $48 \mathrm{hrs}$, it also can occur within $24 \mathrm{hrs}$ if the aseptic method is not proper. Size of cannula and the type of cannula were not very significant, though the risk of phlebitis was more with a particular cannula type as also shown by other studies. ${ }^{16,17}$ Various studies have shown effect of regular change of cannula, ${ }^{15,16}$,infusate used, ${ }^{18,19}$ length of the cannula, site of cannulation on thrombophlebitis. ${ }^{20-22}$ We have also evaluated the some of these risk factors. Interestingly our study also showed that the female gender was predisposed to develop thromboplebitis as shown by previous studies.23, 24 However the most significant risk reducing factor was hand washing. Drawback of our study was that we have not shown the combined effect of all factors on risk of phlebitis. We also have not calculated the cannula survival time with various variables.

Conclusion: Hand washing before insertion of intravenous cannula is the single most important factor that reduces the risk of thrombophlebitis significantly.

Acknowledgement: Dr Mona Sharma senior medical officer and all the other duty medical officers involved in data collection and follow up.

\section{Conflict of interest: none}




\section{References:}

1. David H. Infections due to percutaneous intravenous devices. In, Mandell G, Bennett J, Dolin R, (eds). Principles and Practice of Infectious Diseases, $6^{\text {th }}$ edition. Philadephia: Churchill Livingstone, 2005:3347-52.

2. Fernandez L, et al. Superficial thrombophlebitis of the lower extremity. http://www.uptodate.com/home/index. html. Accessed Oct. 2, 2011.

3. Sutariya B, Berk W. Vascular access. In, Tintinally J, Kelen G, Stapczynski S, (ed). Emergency Medicine, 5th edition. New York: McGraw-Hill, 2000:103-4.

4. Monreal M, Quilez F, Rey-Joly C, et al. Infusion phlebitis in patients with acute pneumonia: a prospective study. Chest 1999; 115:1576-80.

5. O'Grady NP, Alexander M, Dellinger EP, et al. Guidelines for the prevention of intravascular catheterrelated infections. Centers for Disease Control and Prevention. MMWR Recomm Rep 2002;51:1-29.

6. Lundgren A, Jorfeldt L, Ek AC. The care and handling of peripheral intravenous cannulae on 60 surgery and internal medicine patients: an observation study. J Adv Nurs 1993;18:963-71.

7. Singh R, Bhandary S, Pun KD. Peripheral intravenous catheter related phlebitis and its contributing factors among adult population at KU Teaching Hospital. Kathmandu Univ Med J 2008;6:443-7.

8. Cicolini G, Bonghi AP, Di Labio L, et al. Position of peripheral venous cannulae and the incidence of thrombophlebitis: an observational study. J Adv Nurs 2009;65:1268-73.

9. Maki DG, Ringer M. Risk factors for infusion-related phlebitis with small peripheral venous catheters. A randomised controlled trial. Ann Intern Med 199;114:845-54.

10. Uslusoy E, Mete S. Predisposing factors to phlebitis in patients with peripheral intravenous catheters: A descriptive study. J Am Acad Nurse Pract 2008;20:172-80.

11. Pearson ML. Guidelines for the prevention of intravascular device-related infections: Hospital Infection Control Practices Advisory Committee. Infect Control Hosp Epidemiol 1996;17:438-73.

12. Malach T, Jerassy Z, Rudensky B, et al. Prospective surveillance of phlebitis associated with peripheral intravenous catheters. Am $\mathrm{J}$ Infect Control 2006;34:308-12.
13. Erasmus V, Brouwer W, van Beeck EF, et al. A qualitative exploration of reasons for poor hand hygiene among hospital workers: lack of positive role models and of convincing evidence that hand hygiene prevents cross-infection. Infect Control Hosp Epidemiol 2009;30:415-9.

14. De Wandel D, Maes L, Labeau S, et al. Behavioral determinants of hand hygiene compliance in intensive care units. Am J Crit Care 2010;19:230-9.

15. Grune F, Schrappe M, Basten J, et al. Phlebitis rate and time kinetics of short peripheral intravenous catheters. Infection 2004;32:30-2.

16. Nishanth S, Sivaram G, Kalayarasan R, et al. Does elective re-siting of intravenous cannulae decrease peripheral thrombophlebitis? A randomized controlled study. Natl Med J India 2009;22:60.

17. Barker P, Anderson AD, MacFie J. Randomised clinical trial of elective re-siting of intravenous canulae. Ann R Coll Surg Engl 2004;86:281-3.

18. Bregenzer T, Conen D, Sakmann P, Widmer AF. Is routine replacement of peripheral intravenous catheters necessary? Arch Intern Med 1998;158:151-6.

19. McLaren CE, Porter DK, Cohen D. The natural history of intravenous catheter-associated phlebitis. Arch Intern Med 1984;1984:1373-5.

20. Hessov I, Allen J, Arendt K, et al. Infusion thrombophlebitis in a surgical department. Acta Chir Scand 1977;143:151-4.

21. Madan M, Alexandra DJ, Mc Mohan MJ. Influence of catheter type on occurence of thrombophlebitis during peripheral intravenous nutrition. Lancet 1992;339:101-3.

22. Gaukroger PB, Roberts JG, Manners TA. Infusion thrombophlebitis: a prospective comparison of 645 Vialon and Teflon cannulae in anaesthetic and postoperative use. Anaesth Intensive Care 1988;16:265-71.

23. Gupta A, Mehta Y, Juneja R, et al. The effect of cannula material on the incidence of peripheral venous thrombophlebitis. Anaesthesia 2007;62:1139-42.

24. Dennis GM, Marilyn R. Risk Factors for Infusionrelated Phlebitis with Small Peripheral Venous Catheters. A Randomized Controlled Trial. Ann Intern Med 1991;114:845-54. 